editors of JSS have shaped their journal into a broadly based, multidisciplinary publication of consistently high standard. Each of the first four issues contains five to six full-length articles, mainly research reports, and an occasional review. In addition, book reviews and a comprehensive listing of forthcoming events appear at the end of each issue. Abstracts from the meetings of the Society of Sports Sciences, the journal's sponsoring body, are published at appropriate times.

Thomas Reilly and his colleagues have clearly avoided the danger of their journal becoming a place to recycle problem manuscripts - a pitfall that traps many

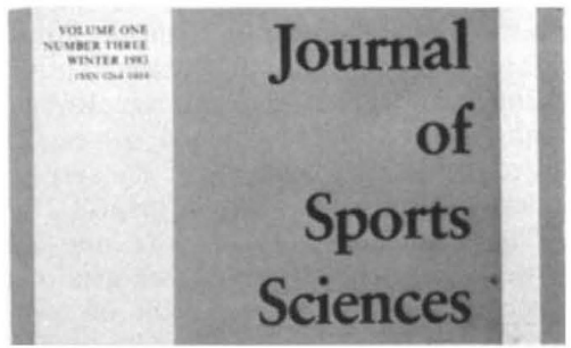

new journals - and the high rejection ratio of $70 \%$ of submitted manuscripts bespeaks the path they have taken to avoid the problem. No indication is given of the time required for review, but the median time from acceptance to publication is a quick two months.

In a field of science that is blossoming over such a range of subjects, it can require superhuman dedication to keep track of the trends in areas in which one is not active. Sports Medicine helps by publishing six issues annually, each of them containing review articles and "leading articles" which are a forum for the communication of key issues in sports science.

Although the journal's title suggests a clinical emphasis, the term sports medicine is used in a general, multidisciplinary sense; for example, articles in the first three issues cover topics as diverse as ergometry, biological rhythms, sports injury, bicarbonate ingestion, cycling physiology, sex and hereditary effects, and endorphins. The quality and depth of the contributions are uneven, as might be expected given such broad scope, but most are useful and well written.

JSS and SM are welcome additions to an area of science in need of deeper as well as broader journal coverage. These two wellexecuted newcomers help meet the need on both accounts.

E.C. Frederick is Director of the Nike Sport Research Laboratory, Exeter, New Hampshire.

- A new book of interest to many researchers in sports science is Thomas A. McMahon's Muscles, Reflexes, and Locomotion. The book is published by Princeton University Press (price hbk $\$ 50, £ 45.80$; pbk $\$ 15, £ 10.70$ ), and will be reviewed in the 11 October issue of Nature.

\section{Eye to eyes}

\section{George Duncan}

Lens Research.

Editor-in-chief Sidney Lerman.

Dekker. 4/yr. \$70 (US),

$\$ 81$ (elsewhere).

Lens Research has been launched upon a stormier sea than are most new journals. Not only do the usual financial stringencies confront it, but the very material that should provide much of the data for the journal - namely, the human lens - is, in many parts of the Western world, removed piecemeal in a messy homogenate rather than as a useful entity. The editor, however, takes a sanguine view of the latter difficulty and believes that it will lead to a rapid improvement in the range of in vivo techniques available for lens investigation.

The journal is produced by photo-offset and aimed at the rapid-publication market. It has a distinguished editorial board to steer it, and to set the tone many of them contributed to the first issue. The articles, all derived from a symposium held in Eindhoven in October 1982, are interesting and well produced. They deal with topics as diverse, but equally important, as the $\mathrm{X}$-ray crystallographic structure of lens crystallins and the in vivo measurement of light-scattering from human lenses. However, a high proportion of the illustrations (I estimate almost $20 \%$ ) in this

\section{Between two cultures}

\section{John Yudkin}

\section{Nutrition and Behavior.}

Editor Robin B. Kanarek.

Alan R. Liss. 4/yr. \$35 (personal); $\$ 70$ (institutional).

IT IS only recently that the traditional nutritionist, concerned with the isolation and description of the nutrients and their effects, began to recognize that the true scope of nutrition embraces the total relationship between people and their food. The subject is therefore based as much on the behavioural sciences as on the experimental sciences. The established journals of nutrition have started to reflect this by publishing occasional papers concerning such matters as food choice and nutrition education. Now comes Nutrition and Behavior, devoted wholly to such matters, with papers dealing with the effects of nutritional status on learning, memory and food choice, as well as with the effects of behaviour on nutrition.

A major problem is that those working in the laboratory sciences and those working in the behavioural sciences have developed attitudes and concepts that are often difficult to reconcile. The first paper issue were reproduced from previous publications. This is an unwarranted intrusion in the first number of any journal, let alone one which purports to cater for the rapid publication market. (At present, it is in fact impossible to judge how quickly the submitted word is converted to the printed page, since neither submission nor acceptance dates are given in any of the issues so far produced.)

The production standard of the journal had slipped badly by the time the third issue appeared, since one article was published with an average print density of 6 words per line and 22 lines per page. I leave the reader to total up this page for comparison. Another article was photo-offset directly from a low-density dot matrix print-out; apart from contravening the published house rules for submission of articles, it was extremely difficult to read - a great pity in this particular case, since the paper described a good study carried out on those precious intact human cataractous lenses.

One most excellent feature of the journal was the inclusion of a comprehensive index at the end of the third issue. If this sort of care could be extended to the production side, and allowance made for comments on previously published articles, then it might be possible to foresee a calm and fruitful voyage ahead for this particular lens flagship.

George Duncan is Reader in Biophysics at the University of East Anglia.

published in the first number of this new journal illustrates the point. Examining the relationship in children (aged from 5 to 16) between refined carbohydrate intake, hair cadmium and cognition, the authors measure food intake by the totally inadequate method of 24-hour recall. They also ignore the frequent demonstration by laboratory workers that hair analysis for mineral elements is quite unreliable. The tables and figures accompanying the paper contain no recognizable data such as the number of grams of carbohydrate and protein in the diet, or the scores of some of the intelligence tests, but are all derived after one or more mathematical transformations.

Later papers published in the four numbers of Vol. 1 of the journal will not be found so frustratingly incomprehensible; perhaps we can now expect the editors to be more critical of what is submitted to them. There is no point in providing a journal that, as they claim, is aimed at "interdisciplinary communication to researchers in a variety of fields" if what is published fails to communicate anything to most of its readers. Yet, if the journal does fulfil its promise, it will be an important contribution to the literature of nutrition.

John Yudkin is Emeritus Professor of Nutrition in the University of London. 